\title{
Substrate Concentration Changes during Pregnancy in the Guinea Pig Studied under Unstressed Steady State Conditions
}

\author{
JOHN W. SPARKS, ${ }^{(25)}$ JEAN-PAUL PEGORIER, JEAN GIRARD, AND FREDERICK C. BATTAGLIA \\ Laboratoire de Physiologie du Development Physiologie, College de France, and Division of Perinatal Medicine, \\ Departments of Pediatrics and Obstetrics and Gynecology, University of Colorado School of Medicine, University of \\ Colorado Health Sciences Center, Denver, Colorado, USA
}

\begin{abstract}
Summary
Weight gain and food intake were measured in unstressed nonpregnant and pregnant guinea pigs fed ad libitum. Nonpregnant females consumed $33.2 \pm 0.5 \mathrm{~g} \cdot$ day $^{-1}$ of pellet diet and did not demonstrate a consistent pattern of weight gain. The average daily food intake of pregnant animals increased linearly from $38 \mathrm{~g} \cdot \mathrm{day}^{-1}$ at 27 days to over $60 \mathrm{~g} \cdot$ day $^{-1}$ near term, and the average maternal weight gain was $13.3 \mathrm{~g} \cdot \mathrm{day}^{-1}$.

Using sterile technique, polyvinyl catheters were inserted under anesthesia into the carotid and femoral arteries of these animals. Animals recovered spontaneously, and catheters remained patent for up to $4 \mathrm{wk}$. The effect of surgical and anesthetic stress was evaluated by measurement of food intake and metabolite levels after surgery. In the nonpregnant animals, blood glucose decreased immediately after surgery $(4.76 \pm 0.36$ versus $5.65 \pm 0.25 ; P<$ 0.05 ), whereas the pregnant animals responded with a substantial increase in blood glucose $(7.57 \pm 0.48$ versus $5.87 \pm 0.33 ; P<$ $0.05)$. Lactate was increased intraoperatively in both groups $(1.76$ \pm 0.22 versus $1.11 \pm 0.07$, nonpregnant; $1.80 \pm 0.17$ versus $1.10 \pm$ 0.08 , pregnant). The pregnant animals differed from the nonpregnant animals with regard to the pattern of changes in blood ketones after surgery. The nonpregnant animals achieved steady state within 1 day after surgery, whereas the pregnant animals required 4 days for recovery. Food intake and maternal weight gain were markedly reduced during the recovery period for the pregnant animals.

Blood metabolite levels were measured in well-fed, unstressed pregnant and nonpregnant guinea pigs. Using measurements made after the third postoperative day, the unstressed pregnant animals demonstrated a progressive decline in blood glucose levels, reaching levels significantly below those of nonpregnant animals at $\mathbf{5 5}$ to 60 and $60+$ days. Arterial concentrations of lactate, pyruvate, $\beta$-hydroxybutyrate, acetoacetate, and free fatty acids did not change consistently with gestation and were not significantly different from nonpregnant values.
\end{abstract}

\section{Speculation}

In animal studies, it is frequently difficult to differentiate the effects of advancing gestation from the effects of acute sample collection. Extension of these techniques of chronic catheterization to other areas of guinea pig metabolism and to other small mammalian species may provide more uniform conditions for the study of the comparative physiology of gestation and fetal development.

The continuation of gestation may present a substantial challenge to the mother. Fetal oxidative and growth requirements, placental metabolic requirements, and requirements imposed by altered metabolism within maternal tissues may, in combination, represent a significant challenge to maternal nutrition and metabolism. The large variations among mammalian species both in fetal growth rate and in fetal body composition might be expected to produce a wide range in caloric requirements for fetal development. The guinea pig is particularly striking in producing a large fetal mass relative to maternal size. By the end of the 68th day of gestation, the total fetal weight accounts for 40 to $60 \%$ of the maternal prepregnancy weight, compared to $5 \%$ in man and $7 \%$ in the sheep. Furthermore, differences in fetal body composition among species will contribute an additional factor in determining the metabolic demand placed upon the mother. For example, the high fat content of the guinea pig fetus (10\%), in contrast to the rat $(1 \%)$ or sheep $(2 \%)$, imposes an additional demand for calories and for carbon. For these reasons, the pregnant guinea pig seemed particularly interesting for the study of the comparative physiology of pregnancy.

Several studies have described the effect of pregnancy upon arterial substrate concentrations in small mammals (5). However, these data are difficult to use in a comparative physiologic approach because blood sampling was done under acute conditions. In large mammals, where studies have been conducted under chronic steady state conditions, the many differences induced by stress upon metabolism and perfusion of tissues have been well described (6). The present study describes an approach which permits sample collection to be carried out under chronic steady state conditions in the pregnant guinea pig. The data provide a description of blood metabolite levels in nonpregnant and pregnant guinea pigs throughout the latter half of gestation.

\section{MATERIALS AND METHODS}

Nonpregnant and pregnant female tricolor guinea pigs were obtained from a commercial breeder. The gestations were dated within 1 day by the date of exposure to the male. Animals were fed ad libitum a vitamin-enriched solid guinea pig diet (No. 114; UAR, Villemaisson-sur-Orge, France). Daily food intake was estimated gravimetrically before and after surgery. Animals were observed to eat continuously throughout the day, although diurnal variation in intake was not quantitated.

Animals were anesthetized with ketamine $\cdot \mathrm{HCl}(60$ to $75 \mathrm{mg}$. $\mathrm{kg}^{-1} \mathrm{IP}$; Parke, Davis \& Co.) and Xylazine. $\mathrm{HCl}$ (4 mg IM; Bayer). They also received atropine sulfate $(0.05 \mathrm{mg} \mathrm{SC})$ before surgery. Using sterile technique, polyvinyl catheters of internal diameter $0.28 \mathrm{~mm}$ and external diameter $0.64 \mathrm{~mm}$ (size V 1 , Bolab, Inc., Derry, NH) were inserted into the maternal carotid and femoral arteries. An operating microscope was found useful for both catheterizations, particularly for the femoral arterial catheter. The femoral artery is approximately the same size as this catheter, and the operating microscope permitted careful observation of the 
tension applied to the vessel at the time of cathether insertion, reducing the risk of perforating the vessel with the catheter tip. The latter complication was the most frequent problem encountered. All catheters were lubricated with Dow Corning silicone oil No. 550 just before insertion in the vessel. Catheters were tied in place, secured with tissue adhesive (No. 910, Eastman Kodak Co.), and tunnelled under the skin to exit into a capped plastic cup (outer diameter, $20 \mathrm{~mm}$ ) sutured to the back of the neck. Animals recovered spontaneously and were provided with unlimited access to food and water; no antibiotics or other medications were given postoperatively. Catheters were filled $(0.01$ to $0.02 \mathrm{ml})$ with a heparin solution (250 units/ml $0.9 \mathrm{~N} \mathrm{NaCl}$ ) and were flushed with this solution after each blood sampling or at least every 3 days. During the initial development of the procedure, approximately $50 \%$ of the pregnant animals failed to tolerate the procedure, as demonstrated by maternal death or abortion of the litter. After standardization of the techniques, approximately $90 \%$ of the operated animals sustained the pregnancy, and catheters remained patent for withdrawal for 2 to 4 wk.

Arterial samples were obtained from the catheters for substrate measurement after withdrawal of at least $0.1 \mathrm{ml}$ of dead space to remove the heparin-saline solution. Animals were housed in a
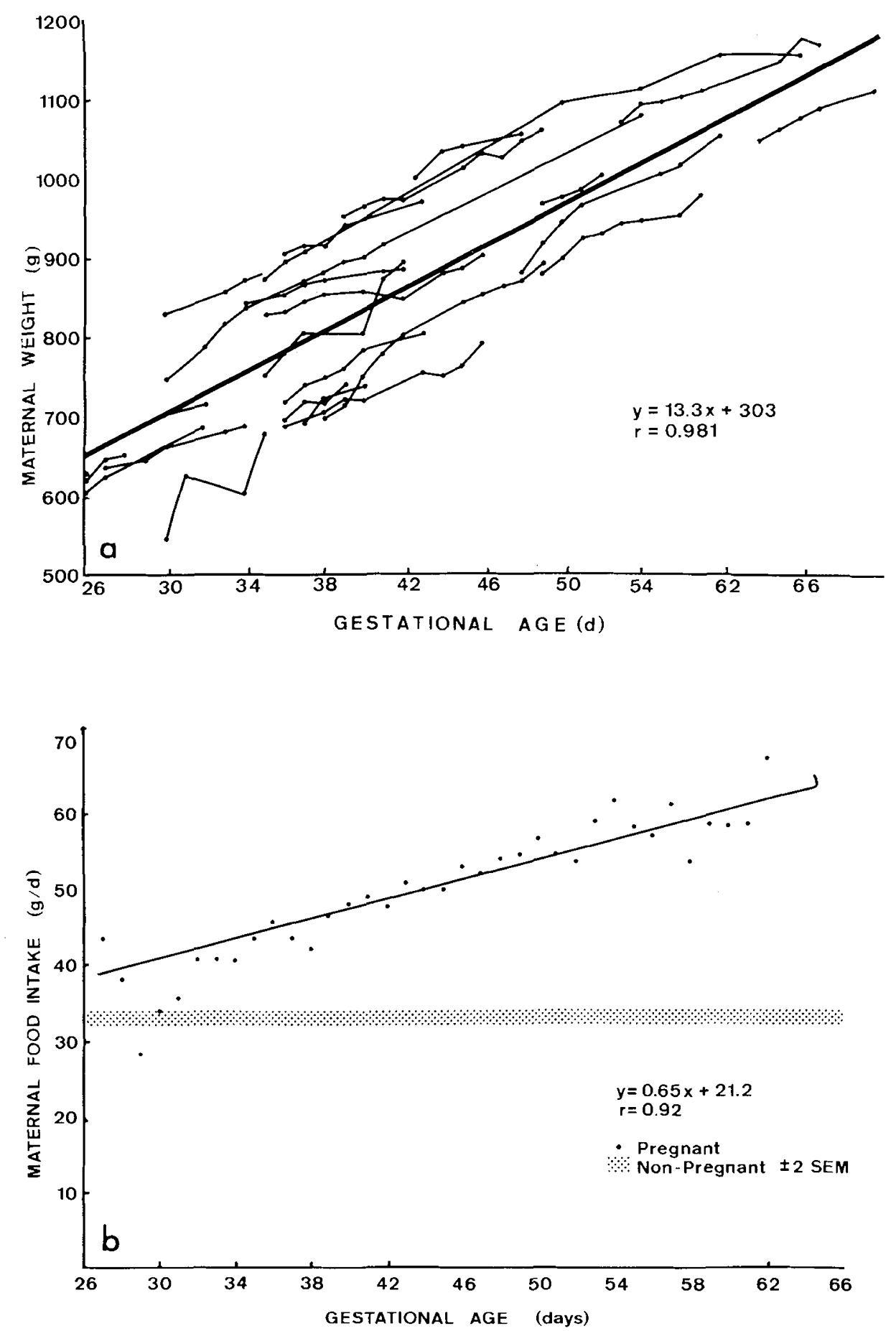

Fig. 1. Serial food intake and maternal weight as a function of gestational age. Mothers were weighed at daily intervals. Weights representing a single animal are connected by a line. Mean maternal weight was calculated at daily intervals, and the mean values were analyzed against gestational age to provide the regression line shown. $1 b$, mean maternal food intakes, estimated gravimetrically in the same animals, at daily intervals. 
light-cycled room with the lights on between 7 AM and 8 PM. Samples were obtained in midmorning. Concentrations of glucose, lactate, pyruvate, acetoacetate, and $\beta$-hydroxybutyrate in whole blood were determined by standard enzymatic methods after perchloric acid precipitation (2). Serum-free fatty acids were determined by the method of Ho (8).

Statistical analysis of substrate values were computed with regard to the number of animals studied in each group and are presented as the mean \pm S.E. If more than one determination was made in an animal in a study group, the mean value of the determinations for that animal was used in calculation of statistics for that study group. Statistical significance for differences between means was calculated by paired or unpaired $t$ test as appropriate.

\section{RESULTS}

\section{MATERNAL WEIGHT GAIN AND FOOD INTAKE}

The present study was undertaken to determine the blood metabolite concentrations in well-fed, unstressed pregnant and nonpregnant guinea pigs. The first part of the study characterized the well-fed animals in terms of maternal weight gain and food intake.

Variations were observed in animal weights, both in nonpregnant animals and in pregnant animals at each gestational age (Fig. 1). Nonpregnant animals ranged from 600 to $750 \mathrm{~g}$ and did not demonstrate a consistent pattern of weight gain. Pregnant animals ranged from $600 \mathrm{~g}$ at 26 days gestation to almost $1200 \mathrm{~g}$ near term.
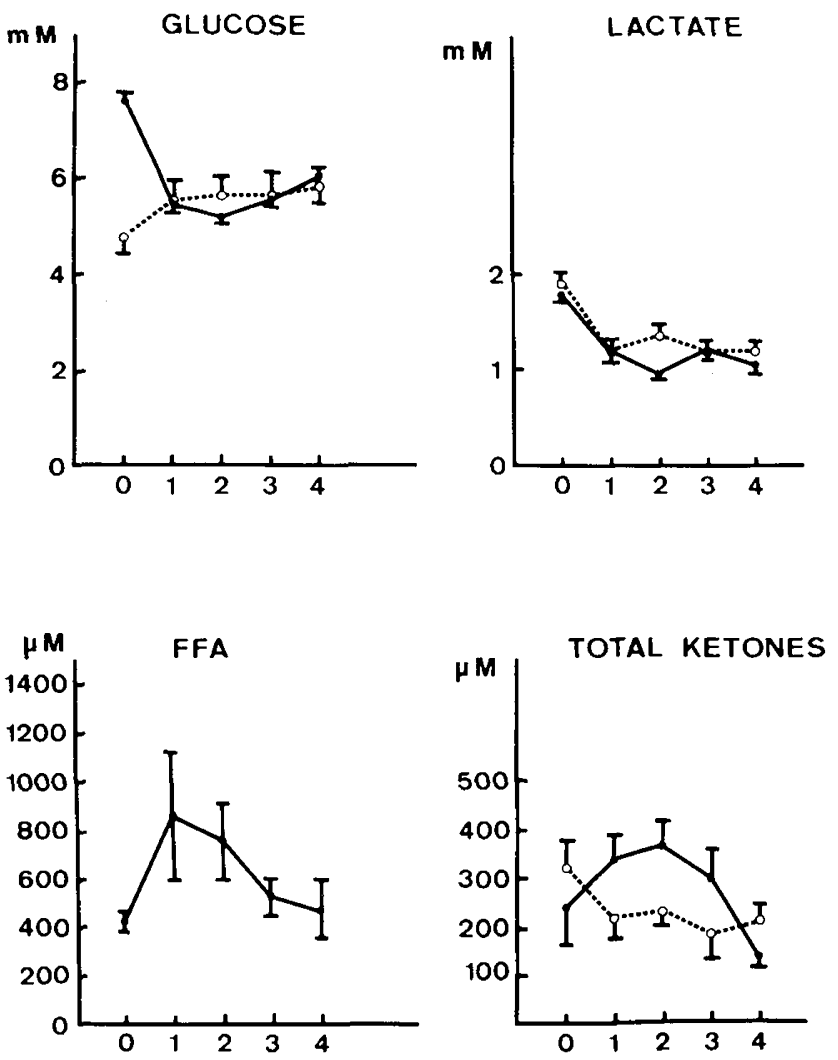

DAYS PAST SURGERY

\section{- Pregnant}

- Non-Pregnant

Fig. 2. Substrate concentrations in arterial blood as a function of days after placement of indwelling arterial catheters. Substrate concentrations are given for pregnant $(\Theta)$ and nonpregnant $(O)$ animals at daily intervals after surgery. Shown are the mean \pm S.E. for at least five determinations. For pregnant animals, only data from animals tolerating the surgical stress were included.
Table 1. Substrate concentrations in pregnant and non-pregnant guinea pigs

\begin{tabular}{|c|c|c|c|c|}
\hline & \multicolumn{2}{|c|}{ Pregnant } & \multicolumn{2}{|c|}{ Nonpregnant } \\
\hline & $\begin{array}{c}\text { Operative } \\
\text { day }\end{array}$ & $\begin{array}{l}\text { Chronic } \\
\text { value }^{1}\end{array}$ & $\begin{array}{c}\text { Operative } \\
\text { day }\end{array}$ & $\begin{array}{l}\text { Chronic } \\
\text { value }^{2}\end{array}$ \\
\hline Glucose (mM) & $\begin{array}{c}7.57 \pm 0.48^{3} \\
(36)^{5}\end{array}$ & $\begin{array}{c}5.87 \pm 0.33^{4} \\
(11)\end{array}$ & $\begin{array}{c}4.76 \pm 0.36 \\
(5)\end{array}$ & $\begin{array}{c}5.65 \pm 0.25 \\
\text { (7) }\end{array}$ \\
\hline Lactate (mM) & $\begin{array}{c}1.80 \pm 0.17 \\
(38)\end{array}$ & $\begin{array}{c}0.98 \pm 0.06 \\
(12)\end{array}$ & $\begin{array}{c}1.76 \pm 0.22 \\
(6)\end{array}$ & $\begin{array}{c}1.17 \pm 0.09^{6} \\
(8)\end{array}$ \\
\hline Pyruvate $(\mu \mathrm{M})$ & $\begin{array}{c}105 \pm 11.2 \\
(32)\end{array}$ & $\begin{array}{c}93.5 \pm 13 \\
(11)\end{array}$ & $\begin{array}{c}106 \pm 24 \\
(6)\end{array}$ & $\begin{array}{c}111 \pm 27 \\
(8)\end{array}$ \\
\hline $\begin{array}{c}\beta O H \text {-Butyrate } \\
\quad(\mu \mathrm{M})\end{array}$ & $\begin{array}{c}146 \pm 24 \\
(33)\end{array}$ & $\begin{array}{c}58 \pm 7 \\
(8)\end{array}$ & $\begin{array}{c}162 \pm 30 \\
(6)\end{array}$ & $\begin{array}{c}101 \pm 9 \\
(8)\end{array}$ \\
\hline $\begin{array}{l}\text { AcetoAcetate } \\
(\mu \mathrm{M})\end{array}$ & $\begin{array}{c}115 \pm 17.8 \\
(32)\end{array}$ & $\begin{array}{c}84 \pm 14 \\
(8)\end{array}$ & $\begin{array}{c}151 \pm 27 \\
(6)\end{array}$ & $\begin{array}{c}100 \pm 12 \\
(8)\end{array}$ \\
\hline $\begin{array}{l}\text { Free Fatty Acids } \\
\qquad(\mu \mathrm{M})\end{array}$ & $\begin{array}{c}428 \pm 34 \\
(15)\end{array}$ & $\begin{array}{c}446 \pm 43 \\
(11)\end{array}$ & $\begin{array}{l}576 \\
(2)\end{array}$ & $\begin{array}{c}447 \pm 44 \\
(8)\end{array}$ \\
\hline
\end{tabular}

${ }^{1}$ Samples drawn after at least 3 days of recovery.

${ }^{2}$ Samples drawn after at least 1 day of recovery.

${ }^{3}$ Mean \pm S.E. For chronic values, a mean value for each animal was calculated for the samples drawn after recovery and these mean values were used to determine the means \pm S.E. for the animals.

${ }^{4} P<0.01$.

${ }^{5}$ Numbers in parentheses, number of animals studied.

${ }^{6} P<0.05$.

There is a linear relationship between gestational age and mean maternal weight gain calculated at daily intervals from 26 to 62 days $(\mathrm{r}=0.98 ; P<0.01)$. The average maternal weight gain was $13.3 \mathrm{~g} /$ day.

Nonpregnant animals consumed an average of $33.2 \pm 0.5 \mathrm{~g}$. $\mathrm{day}^{-1}\left(46.5 \pm 0.5 \mathrm{~g} \cdot \mathrm{kg}^{-1} \cdot \mathrm{day}^{-1}\right)$. The average daily food intake of pregnant animals (Fig. $1 b$ ) increased linearly from $38 \mathrm{~g} \cdot$ day $^{-1}$ at 27 days gestation to over $60 \mathrm{~g} \cdot \mathrm{day}^{-1}$ near term. In the pregnant animals, the increase in daily food intake paralleled the observed increase in weight. Food intake averaged $55.9 \pm 0.7 \mathrm{~g} \cdot \mathrm{kg}^{-1}$. day $^{-1}$ and did not change significantly with gestation. Food intake was significantly higher than the food intake per kilogram for nonpregnant animals $(P<0.001)$. Thus, it was possible to differentiate pregnant from nonpregnant animals by the combination of consistent weight gain and increased food intake as early as the 26 to 30 th day of gestation. In contrast, identification of pregnancy by palpation of fetuses was possible with consistency only by 38 to 40 days gestation.

\section{EFFECT OF SURGICAL AND ANESTHETIC STRESS}

Figure 2 presents the blood metabolite concentrations in pregnant and nonpregnant animals at daily intervals after surgery. In the nonpregnant animals, blood glucose concentration decreased immediately after surgery $(P<0.05)$ and rose to stable levels within the first postoperative day. Similarly, blood lactate and $\beta$ hydroxybutyrate and acetoacetate concentrations were elevated on the operative day $(P<0.05$ for each) and stabilized at lower levels by the first postoperative day. The nonpregnant animals recovered rapidly (Fig. 2), and stable substrate concentrations were found after the first postoperative day (Table 1).

Figure 2 also presents the postsurgical changes in metabolite concentrations for the pregnant animals who maintained the pregnancy after surgery. In contrast to the nonpregnant animals, the pregnant animals responded to anesthesia and surgical stress with a substantial increase in blood glucose concentration $(P<$ 0.001 ). Blood lactate concentrations were elevated on the operative day, similar to the nonpregnant animals.

The pregnant animals differed from the nonpregnant animals with regard to surgical changes in blood ketone levels. Total ketones were elevated in the pregnant animals on the operative day compared to the plateau level reached after 3 days. However, 
unlike the nonpregnant animals, the pregnant animals demonstrated a further rise in total ketones on days 1,2 , and 3 , attaining levels more than two-fold higher than those at the plateau levels reached after day 3 . Free fatty acids showed a similar rise in the pregnant animals, although the operative and plateau levels were not significantly different.

The pattern of transient elevation of ketones and free fatty acids suggested the possibility that resumption of appropriate food intake for pregnancy may have been delayed. Figure 3 confirms that food intake was markedly reduced on the first and second postoperative days and recovered to preoperative levels by day three. Maternal weight gain on the day before surgery averaged $11.9 \mathrm{~g} \cdot$ day $^{-1}$, and during the first 3 days of recovery, it averaged $-14,0.4$, and $11.4 \mathrm{~g} \cdot$ day $^{-1}$, respectively.

A small number of pregnant animals were unable to sustain pregnancy after surgery. Figure 3 shows that this group was associated with a sustained low food intake, and maternal weight gain averaged $-17.9,-24.8$, and $-5.1 \mathrm{~g} \cdot \mathrm{day}^{-1}$ on the first 3 postoperative days in these animals.

\section{SUBSTRATE LEVELS DURING PREGNANCY}

Figure 4 presents the arterial substrate concentrations during the last half of gestation in the guinea pig. Only measurements made after the third postoperative day are included in this analysis. Arterial glucose concentration was elevated in the pregnant animals between 30 and 40 days gestation, compared to the chronic nonpregnant values $(P<0.05)$. In these chronic animal studies, a progressive decline in the blood glucose concentration occurs during the latter half of gestation, reaching levels significantly below the nonpregnant levels at 55 to 60 and $60+$ days $(P<0.05)$. Arterial glucose concentration at term is approximately $70 \%$ of the midgestation level $(P<0.01)$. Arterial concentrations of lactate, pyruvate, $\beta$-hydroxybutyrate, acetoacetate, and free fatty acids did not change consistently with gestation and were not significantly different from nonpregnant values.

\section{DISCUSSION}

The present study clearly documents the effects of operative stress on metabolic parameters in the guinea pig. Glucose, ketone, and lactate concentrations were all altered by the stress of surgical and anesthetic stress in both pregnant and nonpregnant animals compared to steady state values. A major strength of these techniques is the availability of repetitive samples in the same animal,

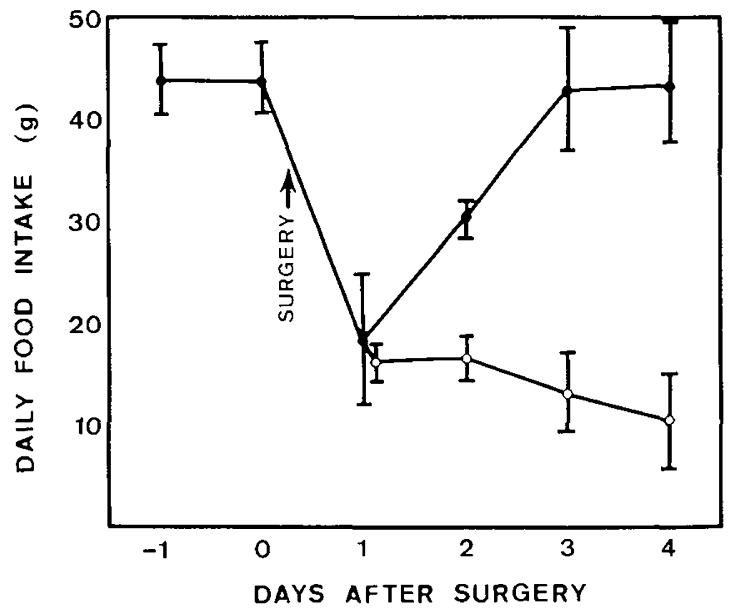

Fig. 3. Dietary intake of pregnant guinea pigs at daily intervals after surgical placement of arterial lines. Seven animals who ultimately aborted or died after the surgery $(O)$ are compared with seven animals $(\bullet)$ who tolerated the anesthesia and surgical placement of catheters. Dietary intake was significantly greater in the latter group at days 2,3 , and 4 after surgery (each $P<0.05$ ). Data are shown as mean \pm S.E.
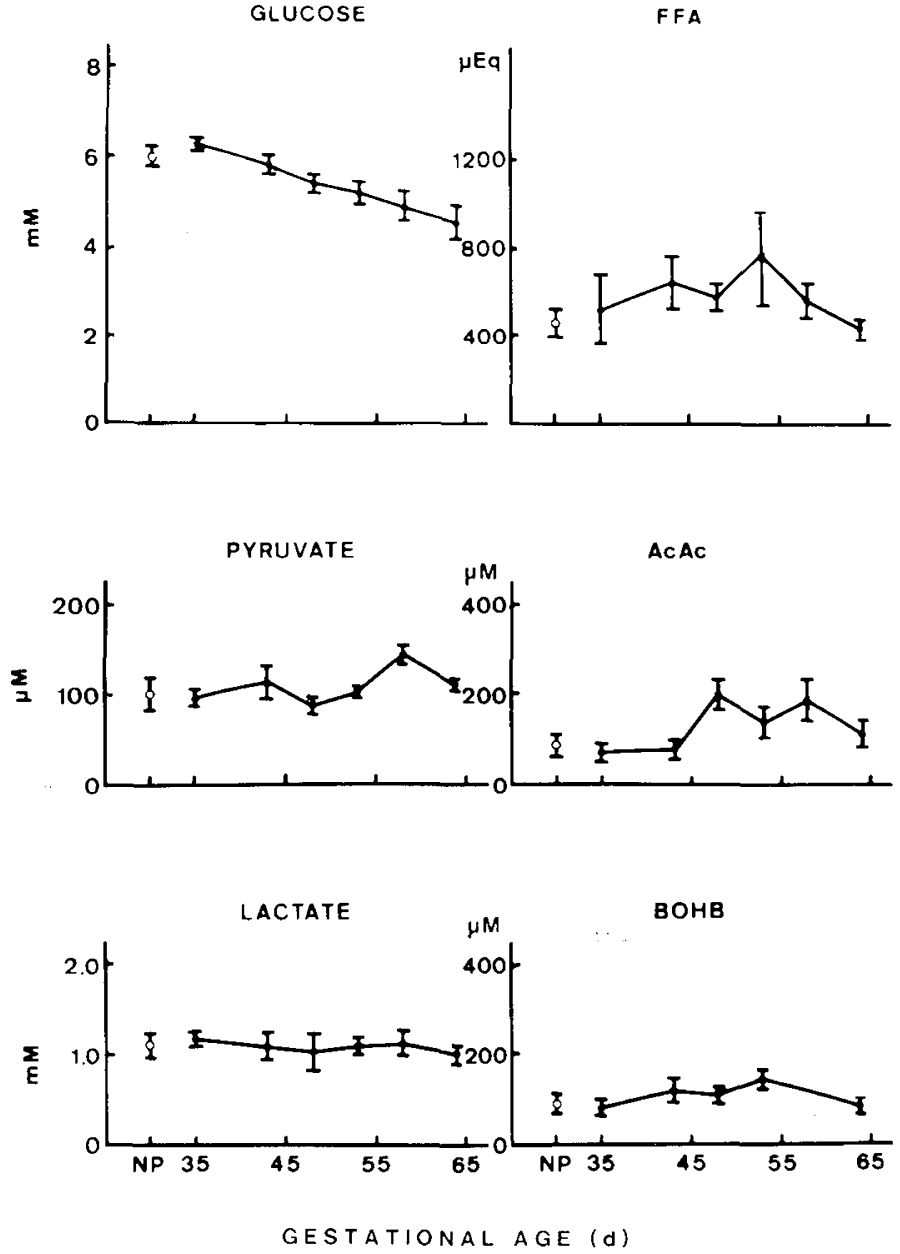

Fig. 4. Arterial substrate concentrations in pregnant and non-pregnant guinea pigs under unstressed conditions. Values shown $(\bullet)$ were determined on arterial samples drawn at least 4 days after surgery. For comparison, the mean \pm S.E. value for unstressed nonpregnant animals $(\mathrm{O})$ is also shown. At least five determinations were made for each point shown.

permitting measurement of steady state substrate values. Application of these techniques thus permits assessment of potential artifact induced by a particular acute sampling technique.

In the present study, the acutely obtained data would have incorrectly identified a much higher glucose concentration in the pregnant compared to the nonpregnant animal, due to qualitatively different responses to the operative stress. Instead, the availbility of chronic catheterization techniques permitted identification of lower pregnant than nonpregnant glucose concentrations in unstressed animals. Further studies will be required to define the conditions necessary for establishment of the chronic, unstressed state when using different anesthetic agents, operative techniques, or species of small mammals.

The guinea pig is remarkable among mammals for the extremely large total free mass, relative to maternal size. At term, 40 to $60 \%$ of maternal weight can be accounted for as fetal mass (9). Only the bats produce as large a fetal mass as a percentage of maternal weight; in their case, however, this is achieved with a much smaller adult size (12). The finding of a $60 \%$ increase in maternal weight during pregnancy is consistent with this large fetal mass, plus the additional contributions of total placental weight and amniotic fluid volumes.

Battaglia and Meschia (1) have hypothesized that fetal $\mathrm{O}_{2}$ consumption is relatively constant among mammals and have emphasized that an implication of this hypothesis for small mammals is that the uterus would represent a relatively "cold spot" 
metabolically compared to the rest of the maternal mass. In support of this hypothesis, Moll et al have estimated the oxygen uptake of the pregnant guinea pig uterus to be $8.8 \mathrm{ml} \cdot \mathrm{kg}^{-1}$. $\mathrm{min}^{-1}$, and that of the extrauterine maternal tissues to be $11.6 \mathrm{ml}$. $\mathrm{kg}^{-1} \cdot \mathrm{min}^{-1}(16)$. For a typical late gestation pregnant uterus weighing $400 \mathrm{~g}$, this rate of oxidative metabolism would require approximately $25 \mathrm{kcal} \cdot \mathrm{day}^{-1}$, assuming a caloric equivalent of 4.9 kcal-liter.

From a nutritional standpoint, the mother must also provide the conceptus with the calories represented in the accretion of new fetal tissue. At birth, the guinea pig fetus has a relatively high fetal fat concentration of $10 \%$ of wet weight (22), and in this respect is similar to the human fetus (23). A gram of new tissue composed of $10 \%$ fat, $15 \%$ non-fat dry weight, and $75 \%$ water would have a caloric value of $1.5 \mathrm{kcal} \cdot \mathrm{g}^{-1}$ so that a normal increment in total fetal weight of $15 \mathrm{~g} \cdot \mathrm{day}^{-1}$ would represent an additional 20 to 25 $\mathrm{kcal} .^{-1}$. Additional calories may also be required to adjust preexisting fetal tissues to changing fetal chemical compositions (20). Summing the calories for oxidative metabolism and represented in new fetal tissue, an estimate of the increment in calories required to sustain the pregnancy in the guinea pig would be 45 to $50 \mathrm{kcal} \cdot \mathrm{day}^{-1}$. The present study demonstrates an increase in maternal food intake of $20 \mathrm{~g} \cdot \mathrm{day}^{-1}$ near term, which, when multiplied by the caloric concentration of the diet $\left(2.7 \mathrm{kcal} \cdot \mathrm{g}^{-1}\right)$ represents an increased caloric intake of $54 \mathrm{kcal} \cdot \mathrm{day}^{-1}$. Although these estimates will undoubtedly be modified as further experimental data are obtained, the approximate agreement of the estimated and the observed increment in maternal caloric intake suggests that a large portion of this increment may be utilized directly in growth and oxidative metabolism of the conceptus.

In spite of the substantial increase observed in maternal spontaneous food intake, maternal arterial glucose concentration fell during gestation. A similar pattern of decrease has been reported in the postabsorptive pregnant human, but of much smaller magnitude $(3,4,13,19,21)$. In the rat, measurements have been made under different conditions of anesthetic and surgical stress and reported glucose concentrations vary widely both in absolute magnitude and in relative trends during gestation $(7,11,15,18)$. Interspecies comparison is made difficult by the differences in feeding patterns among species. For example, an overnight fast in the pregnant rat, which has the bulk of its food intake at night, may be expected to have a quite different impact from a similar fast in pregnant women, where it represents no departure from the usual feeding pattern.

The physiologic and nutritional interpretation of the decrease in maternal glucose concentration in the fed pregnant guinea pig is not certain. The lower glucose concentrations near term do not represent hypoglycemia, relative to an arbitrary standard, but instead define a new set-point for fed arterial glucose concentrations during gestation. Although lower than prepregnant values, these lower concentrations do not necessarily imply an abnormality because the pregnant guinea pig sustains normal growth and metabolism at these levels. Further, we did not observe a consistent change in lactate, pyruvate, or ketone bodies with gestation, as might be expected if the falling glucose reflected a physiologic restriction in intake of carbohydrate or calories from the diet. It is possible that the lower fed glucose concentrations near term reflect alterations in the maternal endocrine mileu.

The present data fail to confirm the gestational increase in plasma free fatty acids previously reported in the guinea pig by others (10). Those studies were carried out on blood samples drawn acutely from the inferior vena cava. Possible explanations for the differences in results include the unstressed sample collection in the present study and the arterial site of sampling. Inferior vena caval substrate concentrations may be altered by the increasing proportion of uterine venous blood flow in the vena cava due to increasing uterine blood flow during gestation. In the human, the free fatty acid concentrations have also been reported to rise (14) or remain unchanged $(4,17)$ in late gestation.
The present study clearly underscores the importance of making metabolic measurements under unstressed, steady state conditions in the small mammal, an observation made repeatedly in the large mammal. It also emphasizes the importance of permitting adequate time for recovery from surgery before making metabolic measurements and points out that the time required for recovery may vary with the parameter to be measured ( $c f$. glucose versus lactate) and with the state of the animal (cf. pregnant versus nonpregnant). Extension of the present techniques to other small mammals will facilitate interspecies comparison of the physiology of gestation. It will be interesting to evaluate the possibility of further refining these surgical techniques to include direct fetal measurements under steady state conditions in the small mammal.

\section{REFERENCES AND NOTES}

1. Battaglia, F. C., and Meschia, G.: Principal substrates of fetal metabolism. Physiol. Rev., 58: 479 (1978).

2. Bergmeyer, H. U.: Methods of Enzymatic Analysis. (Academic Press, Inc., New York, 1974).

3. Edstrom, K., Cerasi, E., and Luft, R.: Insulin response to glucose infusion during pregnancy. A prospective study of high and low insulin responders with normal carbohydrate tolerance. Acta Endocrinol., 75: 87 (1974).

4. Edstrom, K., Perrson, B., Cerasi, E., and Luft, R.: Patterns of free fatty acids, glycerol, $\mathrm{D}-\beta$-hydroxybutyrate and insulin in pregnant women and their newborn infants. Acta Obstet. Gynecol. Scand., 54: 347 (1975).

5. Freinkel, N., Metzger, B. E., Herrera, E., Agnoli, F., and Knopp, R.: Diabetes, pregnancy and the neonate: The effects of pregnancy on metabolic fuels. In: R. R. Rodriguez, and J. Vallance-Owen: Diabetes. Chap. 15 (Excerpta Medica Foundation, Amsterdam, 1971).

6. Gresham, E. L., James, E. J., Raye, J. R., Battaglia, F. C., Makowski, E. L., and Meschia, G.: Production and excretion of urea by the fetal lamb. Pediatrics, 50: 372 (1972).

7. Hererra, E., Knopp, R. H., and Freinkel, N.: Carbohydrate metabolism in pregnancy. VI. Plasma fuelds, insulin, liver composition, gluconeogenesis, and nitrogen metabolism during late gestation in the fed and fasted rat. J. Clin. Invest., 48: 2260 (1969)

8. Ho, R. J.: Radiochemical assay of long-chain fatty acids using ${ }^{63} \mathrm{Ni}$ as tracer. Anal. Biochem., 36: 105 (1970).

9. Ibsen, H. L.: Prenatal growth in guinea pigs with special reference to environmental factors affecting weight. J. Exp. Zool., 51: 51 (1928).

10. Jones, C. T.: Lipid metabolism and mobilization in the guinea pig during pregnancy. Biochem. J., 156: 357 (1976).

11. Knopp, R. H., Saudek, C. D., Arky, R. A., and O'Sullivan, J. B.: Two phases of adipose tissue metabolism in pregnancy: Maternal adaptions for fetal growth. Endocrinol., 92: 984 (1973).

12. Leitch, I., Hytten; F. E., and Billewicz, W. Z.: The maternal and neonatal weights of some mammalia. Proc. Zool. Soc. Lond., 133: 11 (1959).

13. Lind, T., Billewicz, W. Z., and Brown, G.: A serial study of changes occuring in the oral glucose tolerance test during pregnancy. J. Obstet. Gynaecol. Br. Commonw., 80: 1033 (1973).

14. McDonald-Gibson, R. G., Young, M., and Hytten, F. E.: Changes in plasma non-esterified fatty acids and serum glycerol in pregnancy. Br. J. Obstet. Gynecol., 82: 460 (1975).

15. Metzger, B., Pek, S., Hare, J., and Freinkel, N.: Relationship between glucose, insulin and glucagon during fasting in late gestation in the rat. Life Sci., 15: 301 (1974).

16. Moll, W., Kunzel, W., and Ross, H. G.: Gas exchange of the pregnant uterus of anesthetized and unanesthetized guinea pigs. Respir., Physiol., 8: 303 (1970).

17. Perrson, B., and Lunell, N. O.: Metabolic control in diabetic pregnancy. Am. J. Obstet. Gynecol., 122: 737 (1975).

18. Saudek, C. D., Finkowski, M., and Knopp, R. H.: Plasma glucagon and insulin in rat pregnancy. J. Clin. Invest., 55: 180 (1975).

19. Silverstone, F. A.: The rapid intravenous glucose tolerance test in pregnancy. $J$. Clin. Invest., 40: 2180 (1961).

20. Sparks, J. W., Girard, J. R., and Battaglia, F. C.: An estimate of the caloric requirements of the human fetus. Biol. Neonate, 38: 113 (1980).

21. Victor, A.: Normal blood sugar variations during pregnancy. Acta Obstet. Gynecol. Scand., 53: 37 (1974).

22. Widdowson, E. M.: Chemical composition of newly born mammals. Nature (Lond.), 166: 626 (1950).

23. Ziegler, E. E., O'Donnell, A. M., Nelson, S. E., and Fomon, S. J.: Body composition of the reference fetus. Growth, 40:329 (1976).

24. The authors would like to thank Professor Alfred Jost for his support and advice for these studies.

25. Requests for reprints should be addressed to: John W. Sparks, M.D., Newborn Service, B-195, University of Colorado Health Sciences Center, 4200 East Ninth Avenue, Denver, CO 80262 (USA).

26. This research was supported by NIH Program Grant HD 00781; J.W.S. supported by NIH Training Grant HD 07186 . Dr. Battaglia was supported by Josiah Macy, Jr. Foundation Faculty Scholar Award.

27. Received for publication July 22, 1980.

28. Accepted for publication February 10, 1981. 